\title{
Paying it Forward
}

\section{Visual ergonomics on-the-go}

\author{
Jennifer Long ${ }^{\mathrm{a}, \mathrm{b}, *}$ and Hans Richter ${ }^{\mathrm{c}}$ \\ ${ }^{a}$ Jennifer Long Visual Ergonomics, Katoomba, NSW, Australia \\ ${ }^{\mathrm{b}}$ School of Optometry and Vision Science, UNSW Sydney, NSW, Australia \\ ${ }^{\mathrm{c}}$ Centre for Musculoskeletal Research, Department of Occupational and Public Health Sciences, \\ Faculty of Health and Occupational Studies, University of Gävle, Gävle, Sweden
}

Received 15 February 2019

Accepted 14 March 2019

\section{Introduction}

Mobile digital devices have opened up a world of opportunities for work. We no longer need to sit at a desk - we can take our laptop computers, smartphones and tablets with us and work anywhere and at any time.

Working on-the-go also means that we need to look after our own safety and comfort when working: we can't exactly ask the owner of a coffee shop to provide us with an ergonomic chair or help us to set up our digital devices on the table so that we can work more easily.

Vision drives our posture [1]. This makes sense: when we read a book our head goes down, when we look at the ceiling we tip our head backwards.

To help you to set up your digital devices so that they are comfortable and easy to use, we have devised a simple strategy: be mindful of where you are looking and remember - STRAIGHT, DOWN, BIG and CHECK.

\subsection{Straight}

If an object is located to the side of our body, then we will turn our head to look at it [2]. In normal, everyday life, it is fine to turn our head, neck and body to see the world around us. It becomes a problem if we hold a head-turned posture for long periods of time:

*Address for correspondence: Jennifer Long, PO BOX 645, Katoomba, NSW 2780, Australia. E-mail: jlong@ visualergono mics.com.au. after as little as 20 minutes, a head-turned posture can lead to muscle tension in the neck and the shoulders [3].

Consider arranging your digital devices so that the device you are using most of the time is positioned directly in front of you. For example:

- Hold your smartphone directly in front of you instead of to one side of your body (see Fig. 1).

- If your car is your office, then safely park your car, sit in the passenger seat and work with your device on your lap in front of you.

\subsection{Down}

It is much easier for our eyes to focus on close objects when we are looking slightly downward [4]. In general, it is best if the top of a computer monitor is at or below eye height [5].

However, if we need to flex our head and neck forward to view an object (a common posture people adopt when texting on a smartphone) then this could lead to neck problems, especially if the posture is prolonged over a period of time [6].

Consider supporting your device so that it is in a comfortable position for your eyes as well as your arms, neck and back. Options to improve posture and ease of use include:

- Resting your arms on a table while using your smartphone.

- Using a stand for your tablet when reading from the device (see Fig. 2). 

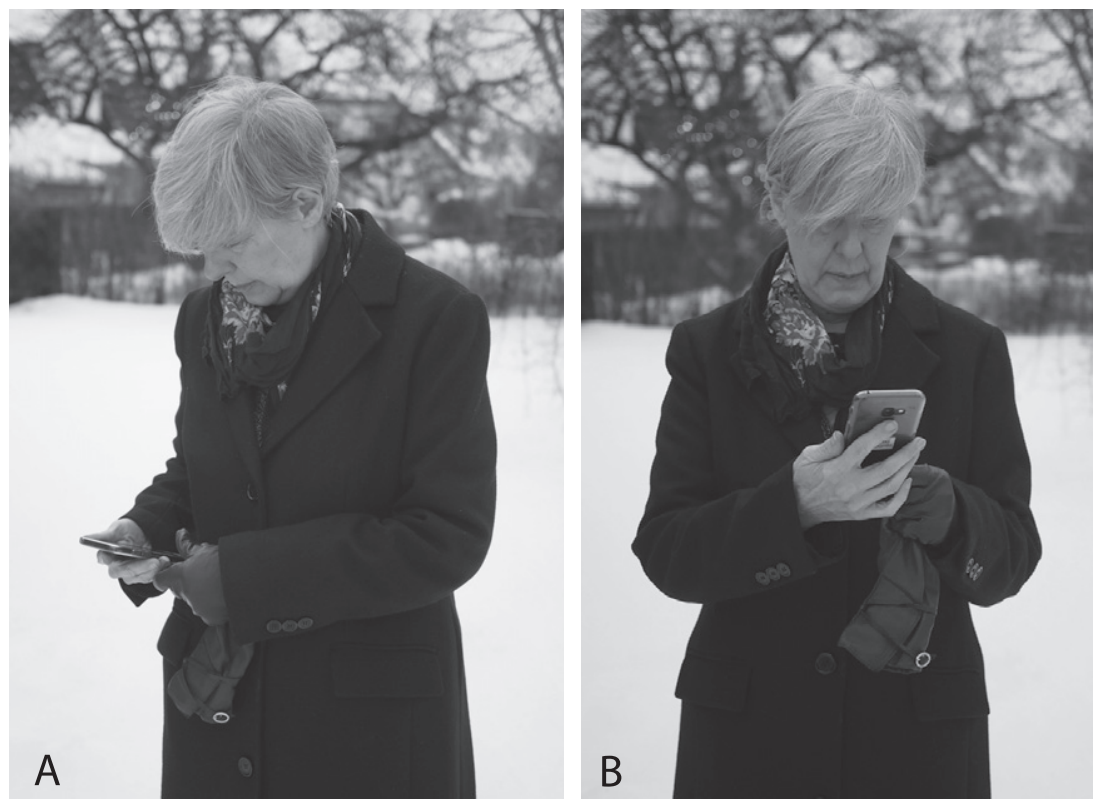

Fig. 1. (A) A head-turned and head flexed forward posture is commonly adopted when using a smartphone. (B) A better posture is to hold the device directly STRAIGHT in front of you (so that your head is not turned to the side). It is easier to focus on the display when it is located DOWN below eye height, but not too low (so that you don't flex your head forward as much).

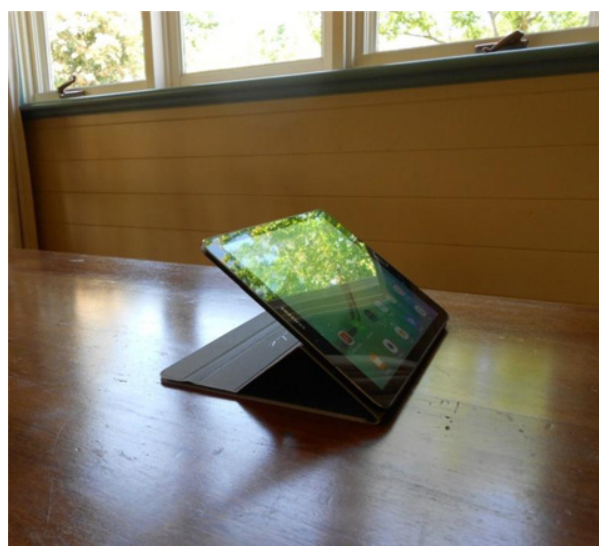

Fig. 2. Using a stand for a digital device means that you don't need to hold the device (freeing up your hands) and you can read from the display without hunching forward over the device. CHECK that there are no reflections on the display (as shown in this image) because this can make the display difficult to read.

- Raising the height of your laptop with a stand or a box - but also use an external keyboard and mouse so that your arms and shoulders remain comfortable (see Fig. 3).

\subsection{Big}

The font size on many mobile devices is very small. Consequently, to read the small size font we may hold

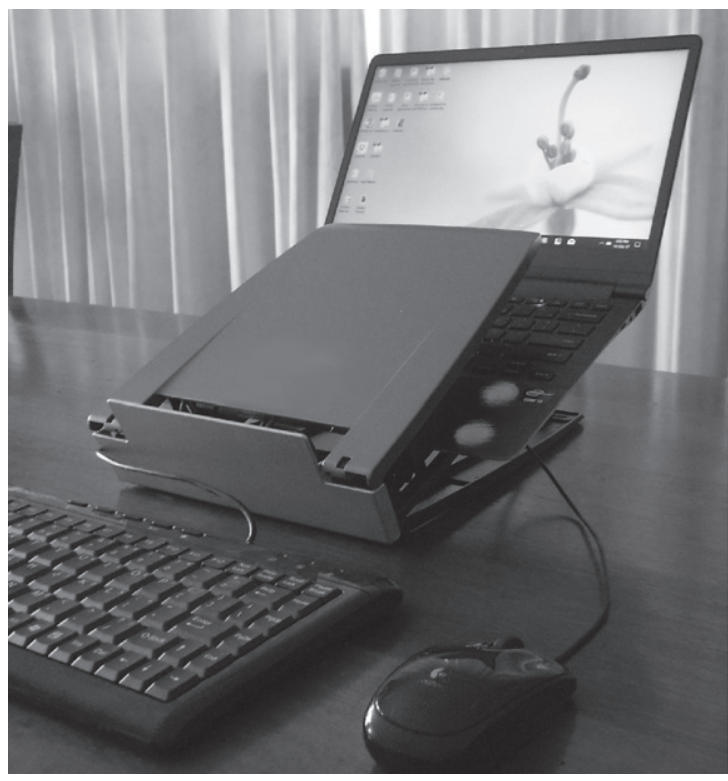

Fig. 3. A laptop stand will raise the height of the monitor so that you don't need to flex your head forward to read from the display. Using an external mouse and keyboard can help your arms and shoulders remain comfortable.

the device closer to our eyes $[7,8]$ or lean forward so that our eyes are closer to the device [9]. These types of postures can lead to eye discomfort and physical discomfort $[8,9]$. 


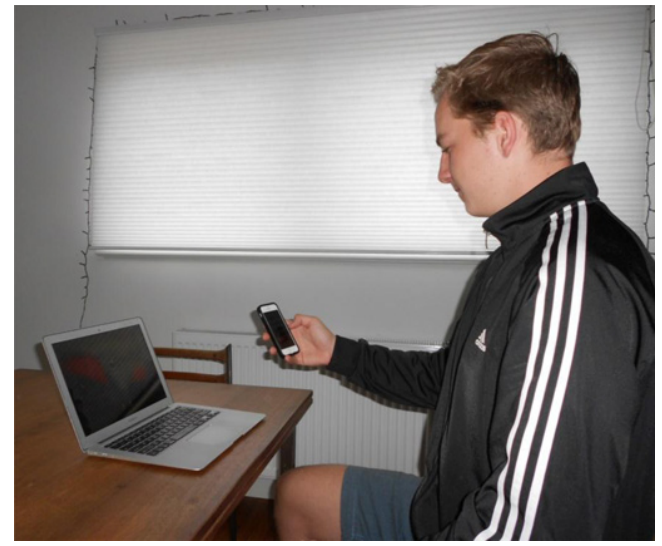

Fig. 4. Use a larger size device if you plan to read for an extended length of time, for example, use a tablet or laptop instead of a smartphone. Then you will be able to view a BIGGER size font and adopt a more comfortable viewing posture.

Consider adjusting the font size on your device so that it comfortable to read. Options include:

- Enlarging the font in the device settings.

- Enlarging the font with an expand gesture on the touchscreen.

- Using a larger device, for example, a tablet instead of a phone, especially if you plan to read from the device for an extended length of time (see Fig. 4).

\subsection{Check}

Everything is set up correctly - the device is straight ahead (STRAIGHT), below eye height (but not too low) (DOWN) and the font size is big enough to read comfortably (BIG). There is still one more thing to do: CHECK.

Check that:

$\checkmark$ There is no reflected light on your device. Otherwise, you may compensate by sitting in an awkward posture to see around the reflection [10]. If there is reflected light on your device (see Fig. 2), then change your position and the tilt of the display to minimize the reflections.

$\checkmark$ Your devices are arranged so that they are comfortable and easy to use. If not, then rearrange them to suit, bearing in mind the importance of STRAIGHT and DOWN.

$\checkmark$ You are taking regular breaks from your work. A regular rest break is good for your eyes, your body and your mind $[11,12]$. Look away from your device every 15 to 30 minutes. Move your body.

$\checkmark$ Your spectacles let you see your work comfortably. If not, then it is a good idea to have an eye examination and discuss your visual needs onthe-go with your optometrist [13]. Take along your devices and show the optometrist how you use your devices. This will help the optometrist prescribe the correct spectacles for you.

$\checkmark$ You are comfortable. If you experience discomfort, then ask someone to watch you while you are working-it's not always easy to know if you holding your body in an awkward posture. Seek help if necessary from a physical practitioner (e.g. a physiotherapist) and take along your devices to the examination to demonstrate how you use your devices. Your practitioner might be able to see what is wrong and offer suggestions for working more comfortably.

Remember that a happy and comfortable worker also makes for a more productive and efficient worker.

\section{Conflict of interest}

None to report.

\section{References}

[1] Villanueva M, Sotoyama M, Jonai H, Takeuchi Y, Saito S. Adjustments of posture and viewing parameters of the eye to changes in the screen height of the visual display terminal. Ergonomics. 1996;39(7):933-45.

[2] North R. Work and the Eye. 2nd ed. Oxford, Great Britain: Butterworth Heinemann; 2001.

[3] Szeto G, Sham K. The effects of angled positions of computer display screen on muscle activities of the neckshoulder stabilizers. International Journal of Industrial Ergonomics. 2008;38:9-17.

[4] Ripple P. Variation in accommodation in vertical directions of gaze. American Journal of Ophthalmology. 1952;35:1631-4.

[5] Burgess-Limerick R, Mon-Williams M, Coppard V. Visual display height. Human Factors. 2000;42(1):140-50.

[6] Lee S, Kang H, Shin G. Head flexion angle while using a smartphone. Ergonomics. 2015;58(2):220-6.

[7] Bababekova Y, Rosenfield M, Hue J, Huang R. Font size and viewing distance of handheld smart phones. Optometry and Vision Science. 2011;88(7):795-7.

[8] Long J, Cheung R, Duong S, Paynter R, Asper L. Viewing distance and eyestrain symptoms with prolonged viewing of smartphones. Clinical and Experimental Optometry. 2017;100(2):133-7.

[9] Rempel D, Willms K, Anshel J, Jaschinski W, Sheedy J. The effects of visual display distance on eye accommoda- 
tion, head posture, and vision and neck symptoms. Human Factors. 2007;49:830-8.

[10] Tegtmeier P. A scoping review on smart mobile devices and physical strain. Work. 2018;59:273-83.

[11] Balci R, Aghazadeh F. The effect of work-rest schedules and type of task on the discomfort and performance of VDT users. Ergonomics. 2003;46(5):455-65.
[12] Galinsky T, Swanson N, Sauter S, Hurrell J, Schleifer L. A field study of supplementary rest breaks for data-entry operators. Ergonomics. 2000;43(5):622-38.

[13] Long J. Prescribing for a computer user. In: Rosenfield M, Lee E, Goodwin D, editors. Clinical Cases in Eye Care. Philadelphia: Wolters Kluwer; 2019, pp. 40-3. 